\title{
The problem of urban design universals: modeling and planning of ensemble spaces
}

\author{
Sergey Norenkov ${ }^{1}$ Evgenia Krasheninnikova ${ }^{1, *}$ \\ ${ }^{1}$ Nizhny Novgorod State University of Architecture and Civil Engineering, 65, Ilyinskaya St., \\ 603000, Nizhny Novgorod, Russia
}

\begin{abstract}
The purpose of the article is to pose the problem of the universals of urban design and show schematic features of its solution in modeling and planning ensemble spaces of modern cities. An integral, correlatively universal model of urban design is yet to be created in the paradigm of sustainable development of "smart garden-cities" - as opposed to stochastic random development processes of urban territories following some quick-fix projects. Deductive and inductive methods are proposed as a basis. The general methodology is developed in the spectrum of transitions from generalized vision in the logic of universals, to particulars, revealing in the specifics of the unique. In a city that lives its own life, as a kind of faceted, multisided "Philosopher's stone", the universals are present everywhere and realized in the consistency of each and every element. Urban ensemble spaces that organically link the unique expressiveness of every historical chronotope gain their own algorithms in the process of urban design, supported by modeling and planning. The main results relating to the productivity in application of the universals as criteria for the estimation of architectural urban design were obtained in the design activities of the LLC "SynARChiya" and in the educational process in Nizhny Novgorod State University of Architecture and Civil Engineering.
\end{abstract}

\section{Introduction}

A city is a universal phenomenon of human civilization in the entirety of its economies and cultures. It is a kind of expressive "Philosopher's stone" that people tried to discover and actually created over long periods of time. In search of different interpretations of the "Philosopher's stone", we adhere to our own interpretation that appeared many times in our scientific publications stating that it is the "city" in the entire variety of its full-fledged implementations on the planet Earth. The basic element in identifying the universals is the need experienced by professional designers to determine the measure of significance concerning the dominant "facet $=$ criteria" of the ensembles under design and reconstruction which is very relevant today.

The architecture of the city is a "Stone chronicle" that has been written, is being written and will be written in the language of architecture as long as there exist the profession of architects, urban planners, designers and many other specialists and people involved in the

\footnotetext{
*Corresponding author: krash_es@mail.ru
} 
reproduction of the vital forces supporting urban ensembles. The love of wisdom is the essence of life patterns and laws that must be fixed in projects implementation. In terms of unity of diversity envisaged in individual design stages of a comprehensive town planning, the combination of the notions "philosophy" and "stone" is something that must not be rejected in any way striving for the highest quality of creation, recreation, and reproduction of cities as living chronotopes of the "stone wisdom". They are formed in a specific place to address specific needs of people who act in their proper time mentally when creating urban ensembles.

In the logic of common ground, in understanding how urban design determines the historical facts of urban development, the problem of universals stands forth [1]. The need to identify the universals as important initial professional grounds for urban design is intensified by the activities of mass civil movements standing for high quality public aminities, comfort for people in their places of residence and tourists facilities [2].

The language of graphic communications, the conceptual and terminological system of city architecture represent the basic original universals of urban design, though they are not limited to them only. The Russian Encyclopedia of Architectural and Construction in its 15 volumes makes indispensable contribution to the communication of specialists in the appropriate fields. Its entire interrelated field of concepts is usually specified in the normative reference literature, regularly subjected to proofreading, revision and amendments, and in popular scientific publications. Professional thinking systematically collects data from architectural public spaces making amalgamated ensembles, among other things through typical universals of tectonic integrity in the functional cyclicality, structures, and forms [3].

Why should we necessarily address the problem of universals as one of the primary professional issues in a broader and more thorough context? This is so, not only because, without revealing common problems, we will not be able to confidently and effectively solve many individual issues, stumbling on more complex events in the field of urban design. We should also understand the conflicting information flows associated with successful promotion of project design products. The problem of universals is also important because of the infinite complexity of project activities, involving very large number of people interested in long-term positive results. In the context of cyclical ongoing global, regional and local crises and the need for sustainable development of urban spaces, the intensified search for the necessary and sufficient sets of universals becomes very important, due to cultural and philosophical paradigms, but also to the newest emerging large scale projects and their implementation [4].

\section{Materials and methods}

One of the authors of this paper remembers very well the complexities of the public space project located in one of the main squares in the city of Tver (Kalinin). The design work involved joit efforts with participation of the city chief architect and a group of specialists. Several architects of GRAZHDANPROJECT offered their solutions, but each time the proposals were rejected by their colleagues. After the ultimate approval of the final project decision comprising the monument to Saltykov-Shchedrin, pedestrian links between the local theater, circus, street spaces, landscaping works, fountains, and thoroughly studied General plan details, the authors were satisfied. Nevertheless, after the completive implementation of the project with changes and some deterioration, in the end the authors felt disappointment. The complexity of urban design in that case once again proved that not only designers are responsible for the successful promotion of ensemble integrity, but also a very large number of people involved who may unwittingly influence the final result. 
In the most general case, the problems of urban design universals should considered starting from the primary issues of the architectonics of human space. They are related to city architecture philosophy, scientific knowledge, art effectiveness, computer equipment, worldview, ideology, and many others. These problem areas directly depend on solving the most challenging issues of educational prospects, scientific and technologocal progress, and other things particularly those usually included in functions performed by universities. Universe and University are cognate words, and the problem set in the title may be given only general consideration in one article, at the maximum. We discuss only the most general fundamentals of universals in special literature. Within the framework of the general range of problems, like-minded experts refer the notion "socio-" to human, "anthropo-" to people, "syn-" to the whole and simultaneous, "archi-" - to supreme, "tectonics" - to organization in these fundamentals. Judging by the experience of the authors' publications, the proposed notions can be brought together in fundamental categories like socioanthropology and synarchiotectonics (see the authors' publications in the RSCI).

The problem of universals is derived from the general issue of human knowledge of the universe and understanding of reality in the aspect of "everything in everything". In our case, the problem of universals primarily affects the most complex issues concerning the architectonics of project activity, humanitarian technologies, and the living "centermost" hierarchy. They provide solutions to complex urban design issues, as well as more complete and substantiated development of urban ensemble spaces modeling and planning. Complex, harmonious and comprehensive urban design involves an infinite number of issues and to understand them in all their intricacies requires understanding by specialists of different profiles brought together by the common cause of getting an insight into universals, so as not to harm future generations.

The problems of synarchiotectonics of urban design, in their own way, systematically repeat and fractally and holistically reflect the problems of architectonic arts, the architectonics of sciences and the architectonics of telematics. We primarily refer to architecture, urban planning, and design as architectonic arts. In project-oriented vector providing for sustainable city development, we see the architectonics of research and project design activities in organic synthesis as a unified science of sciences, in accessible and communicatively open interdisciplinary connections of basic and applied sciences coordinated by philosophy and general theory of systems. This determines the professional level of specialists capable of developing real projects, including regional and nation-wide ones.

In their unity and organic integrity in making final decisions, representatives of science and art are responsible for their proper sections of the design decision making relating to the future project, its organic inclusion in the structural and functional-genetic morphology of the ensemble. At the same time, the authors consider the architectonics of telematics, which combines the procedures of scientific and artistic creativity into a single whole, by means of technical and technological support of all stages of urban design integrated with modeling, programming and planning. The authors attach special importance to socioanthropological universals in the information technology and computer support of urban design. Significant and promising developments are expected here in relation to the "smart home-city", based on innovations in the field of artificial intelligence.

\section{Results}

In order to better understand what the authors mean when they speak about the humanity of the environment, and its anthropogenesis, we present some figurative model, the key element of which is "human individual" and his ability to create new intellectual products, 
which include architectural design and urban development projects. The simplified scheme of such a model may be explained by analogy with the architectonics of the human brain, with its right and left hemispheres movably "resting" in the skull construct and on the muscular-vertebral connections of the vertebral column. In the reality of life, all the system additionally moves, together with the human body, along the trajectories that are decided by the brain.

Schematically, it is not very difficult to present this extremely simplified model in correlation of its elements as an integral unity of Sciences and Arts (right and left brain hemispheres), as well as Designing, Programming, Planning, Forecasting, and TechnicalTechnological elements (musculoskeletal, nervous, and circulatory-lymphatic systems that form the basis of human viability). The phenomenon of active participation of future clients in the organization of local complex projects and ensemble spaces, historically gain momentum, especially at the early stages of urban design. This also becomes even more developed at the final stages of a professional project design, taking into account the phenomenon of its artistic integration [5].

Of course, this is a great simplification concerning the results, but in our further discussion of the role of socio-anthropological problems it represents even more a supercomplex system revealed by means of universals. This is easily proved by the fact that in the design work performed by of creative teams, the entire variety of issues is much more difficult, if we take into consideration the projected results expected in twenty years ahead. Many times repeated human consciousness, together with human beings who carry it, each time implement the fragments of their common cause in new actions and activities. And these are only individual elements of the urban design activities realized by the participants in the general process of urban ensembles creation, following sustainable development or failing to keep to that principle, and making them into a system of end-to-end chronotopes of ensembles. In a particular case, from the standpoint of the authors, the logic in the development of the universals can procede from the "brick style" [6].

Historically mobile and modern urban design work cyclically overcomes the paradoxical metamorphosis of design transitions from traditional and typical to avant-garde and innovative. As the need for individualization of project design processes becomes more and more established, the creative potential of project design teams is increasingly supported by computer programs of the latest generations. The prospects of growing urban community socialization result in the fact that ordinary people are increasingly included in the design and urban development activities. "Socio" and "anthropo" are formed into a relatively complete universal of the socioanthropological vector, very rarely developing into a perfect integrity. Apparently this is due to a huge set of conditions, circumstances, and resources. The real value of such phenomena is usually assessed in the course of international recognition of urban ensembles, for instance at the level of the UNESCO or the in the register of monuments having national significance. Universals are the nodal points of codes in the "decision tree" of urban design. In the future, multifaceted ideas involving self-developing universal systems still have to be transferred from their tabular forms to three-dimensional ones, and further on to network and space-time models. Modeling of dynamic chronotopes pertaining to uninterrupted continuum of co-scaled hierarchies in the construction of ensemble spaces should be developed in the unity of design, planning and programming (Tables 1-3). 
Table 1. Universals in the aspects of the subject-humanistic integrity of synarchiotectonics and socioanthropology (initial human resources and creation materials).

\begin{tabular}{|l|l|l|l|}
\hline $\begin{array}{c}\text { Syn } \\
\text { (Temporal Whole) }\end{array}$ & Archi (Higher) & \multicolumn{1}{c|}{$\begin{array}{c}\text { Techtonics } \\
\text { (Organization) }\end{array}$} \\
\hline \multicolumn{5}{|c|}{ Synarchitectonics } & \\
\hline & & Universals & Anthropology \\
\hline
\end{tabular}

Table 2. Universals in the aspects of expedient urban design, modeling and planning actions (operations, processes, traditions and innovations).

\begin{tabular}{|l|l|ll|l|}
\hline Model & Layout & Plan & Planning \\
\hline \multicolumn{3}{|c|}{ Modeling } & \multicolumn{3}{c|}{ Planning } \\
\hline Forecast & \multicolumn{3}{|c|}{ Universals } \\
\hline \multicolumn{3}{|c|}{ Urban Design } \\
\hline \multicolumn{2}{|c|}{ City } & \multicolumn{2}{c|}{ Project } \\
\hline
\end{tabular}

Table 3. Universals in aspects of sustainable civilizational development, taking into account the use of valuable knowledge and skills in obtaining products (specific goals and reproducible integrities of spatial ensembles).

\begin{tabular}{|ccc|}
\hline The Science & Art \\
\hline \multicolumn{3}{|c|}{ "Philosopher's Stone" } \\
\hline \multicolumn{3}{|c|}{ Universals } \\
\hline Civilization \\
\hline Economy & Culture \\
\hline
\end{tabular}

\section{Discussion}

Social and anthropological universals are manifested primarily in the many-sided activity of creative individuals versatile and unique in their professional responsibility. They accumulate and integrate collective bodies and teams that include the necessary and sufficient number of scientists, artists, technicians, economists, cultural scientists, and managers. They mention the names of a wide range of creative personalities who have made and continue to make a notable contribution to urban design widely represent global professional creativity of the people who dedicate their work to the prosperity of large, great, and small historical cities of our planet.

It is extremely difficult to take into account probabilistic solutions of new design decisions in various forms architectural environment not yet known, and only highly qualified and competent specialists can solve the relevant long-term problems. Modeling for urban design is essential in a number of aspects relating to the expression of creative approaches and representation of scientific and artistic horizons of interaction with scientific and technological progress. First of all, project analysis and research synthesis provide broad opportunities for generalization and signification of the data related to history and theory, methodology and criticism of the "body" of architecture. The problem area involving concrete definition of the "body" of architecture helps getting an insight into the urban design particularities [7]. In the cultural and artistic tradition of project design creativity, it is of great importance to produce substitutes for project design objects in the form of models. This is mostly important at the intermediate stages of project design using software and practicing well-reasoned analysis of the design solutions presented by the developers. 
Modeling represents replacement of the nature and real project with sign-symbolic and graphological results or the models proper that appear in different degrees of approximation to the original source, the projected object proper as a chronotope (maquette, scale and operating model, simulator) or an art object set apart from it in its meaning and content (installation, performance, simulacrum). Classical tradition and modern city architecture influence the methods of urban design involved in most various urban ensembles [8]. In the course of modeling maximalistic and minimalistic trends in the particular strategies of urban design are associated with traditions [9].

The graphology of modeling in its internal synarchiotectonic integrity is unfolded into the full-scale transition of the urban design to monitoring and forecasting, planning and programming. The entire range of multi-sided aspects and points of architectonic creativity in its full representation is revealed in architecture, urban planning, and design as a fundamental system-forming complex of sustainable development of the second nature. In maintaining its more viable environmental component, the prominence is given to subsystem gradations relating to the segments of urban design participants such as landscaping, exhibitions, monumental and decorative arts, art-street-activities, etc. The standards in green architecture unperceivably exert their influence on all urban design activities [10].

In application to the analysis of urban design as a whole, we can not ignore planning activity in its two main interpretations and in application in practice: spatial and temporal universals. In the spatial dimension, the concept of a plan unfolds, starting with the geometry of the drawing representation of the future object, fixed in the project, and futher its implementation in the planning structures of the real city in itself. In the temporal aspect, the plans characterize the procedural sequence, the flow over time of both the project activity and its implementation in the construction activity according to the project time schedules. Strategic planning as viewed from information systems influence project development methods in urban design [11].

The planned organization of the ensemble space proceeds in time by key objects created according to schedules, road maps, and guidebooks. In its perception, urban architecture determines the specific aspects of modeling and planning [12]. Project management implies attracting the best teams on a competitive basis, composed of researchers and designers, whose competence is based on particular attention to the dynamics and statics of chronotopes. For example, the problem area including ecological tourism may be fundamentally regulated by the design activity universals [13]. In their most general form, they concentrate on solid unity of categorical components both temporal ("Chronos" in the three statuses "A - Past, N - Present, W - Future") and spatial ("topos" in the three dimensions specified and linked to topography as X - "length", Y - "height", Z - "width"). The mathematical modeling of socio-economic processes enriches the planning quality aspects in urban design [14].

Planning of the urban design sustainable development is carried out by successive interrelated cycles divided into scores to hundreds of sections and subsections including individual components like preliminary project design ("concept-project, fore-project, sketch-project"), project design proper ("design document, working design"), complete design ("working construction documents", " working construction documents detailing"), project implementation supervision (outgoing documents log, supervision register, technical supervision register). Infographics for urban design can be elaborated all the way to a separate building [15]. In urban design as creative activity of grate importance are multicultural design issues where universals should also be used in as criteria for the success of collective efforts.

\section{Conclusions}


1. Human, humanitarian, anthropological universals reflect important typical problems of architecture, for all its millennial history traditionally lining up in response to needs and abilities, opportunities and resources for people seeking to gather in the creative community to achieve the objectives of urban design, creation and reorganization of ensemble spaces, and accordingly, there is the unfolding derivative problems, which is based on socioanthropological models, plans, programmes.

2. The problem of integral integrity of sustainable urban design is reflected in the universals of project chronotopes and is solved using the category of synarchiotectonics in the unity of the concepts "sin" (whole, unified, system), "arch" (higher, hierarchical, power), "tectonics" (function, construction, form, material). In a consolidated form, the above-mentioned categories formed in the interaction of series of groups as universals can be transformed into a smaller or larger number of concepts.

3. Ideally, scientific constructions of interrelated parts of the theory, history, methodology and criticism of architecture, it is possible to deploy relatively coherent paradigm system of universal socio-anthropo-sinergicheskoe tectonics, concentrated modeling and planning obtaining the final product of the project activity represented in the set of sections of the working documentation, able and ready to be a law for implementation in manufacturing and construction.

4. Modeling of urban design in expanded form can be specified in the three-dimensional matrix of universals with three key vectors Energietechnik: architectonic of the Sciences (the General systems theory, fundamental and applied science), architectural art, key types (architecture, urban planning, design), architectonics of telematics subsystems (technology, technology, computer science).

5. The main criteria for building a more complete system of universals in urban design management, built in the General structure of the above-described universals of socioanthropological synarchiotectonics and depending on the complexity of the sets of objects of urban ensembles of specific projects, are the following: adequacy, reliability, comprehensiveness, interest, awareness, quality, monitoring, observability, objectivity, positivity, consistency, predictability, professionalism, effectiveness, consistency, comparability, manufacturability, digitalization, efficiency, heuristics, environmental friendliness, economy, ergonomics.

\section{References}

1. N. Saprykina, International Conference on Architecture: Heritage, Traditions and Innovations (AHTI 2019), 376-380 (2019) doi: 10.2991/ahti-19.2019.70

2. A.L. Gelfond, International Conference on Architecture: Heritage, Traditions and Innovations (AHTI 2019), 446-451 (2019) https://doi.org/10.2991/ahti-19.2019.83

3. A.L. Gelfond, Architecture of public spaces (INFRA-M, Moscow, 2019) DOI: 10.12737/monography_5b7a73a7d8a082.42460125 p.412

4. M. Nevlyutov, International Conference on Architecture: Heritage, Traditions and Innovations (AHTI 2019), 295-299 (2019) DOI: 10.2991/ahti-19.2019.55

5. M.V. Dutsev, International Conference on Architecture: Heritage, Traditions and Innovations (AHTI 2019), 452-456 (2019) doi: 10.2991/ahti-19.2019.84

6. S.V. Norenkov, E.S. Krasheninnikova, A.V. Krasheninnikov, Stroitelnye materialy 12, 13-17 (2019) DOI: https://doi.org/10.31659/0585-430X-2019-777-12-13-17

7. L. Li, Q. Zhang, M. He, IOP Conf. Ser.: Mater. Sci. Eng. 690, 1012017 (2017) doi:10.1088/1757-899X/690/1/012017 
8. Yu Jiang, IOP Conf. Ser.: Earth Environ. Sci. 267, 052017 (2019) doi:10.1088/1755$1315 / 267 / 5 / 052017$

9. Yu. N. Lukito, B. P. Handoko, IOP Conf. Ser.: Mater. Sci. Eng. 316, 012006 (2018) doi:10.1088/1757-899X/316/1/012006

10. W.S. Abioso, IOP Conf. Ser.: Mater. Sci. Eng. 662, 042019 (2019) doi:10.1088/1757$899 \mathrm{X} / 662 / 4 / 042019$

11. M. Sidiq, I.D. Sumitra, IOP Conf. Ser.: Mater. Sci. Eng. 662, 022057 (2019) doi:10.1088/1757-899X/662/2/022057

12. M. Skaza, IOP Conf. Ser.: Mater. Sci. Eng. 471, 022033 (2019) doi:10.1088/1757$899 X / 471 / 2 / 022033$

13. D. Astanin, E3S Web of Conferences 138, $01013 \quad$ (2019) doi.org/10.1051/e3sconf/201913801013

14. V. Okrepilov, N. Chetyrkina, M. Krylov, E3S Web of Conferences 138, 02008 (2019) doi.org/10.1051/e3sconf/201913802008

15. K. Losev, V. Chulkov, E3S Web of Conferences 138, 02009 (2019) doi.org/10.1051/e3sconf/201913802009 